\title{
Produção e qualidade de pastagens de Coastcross- 1 e milheto utilizadas com vacas leiteiras
}

\author{
Production and quality of Coastcross-1 and pearl millet pastures utilized with dairy cows
}

\author{
Luciene Fernanda Barros Scaravelli ${ }^{\mathrm{I}}$ Lilian Elgalise Techio Pereira ${ }^{\mathrm{I}}$ \\ Clair Jorge Olivo ${ }^{\text {II }}$ Carlos Alberto Agnolin ${ }^{\mathrm{I}}$
}

\section{RESUMO}

O uso de pastagens do gênero Cynodon, em propriedades leiteiras do Rio Grande do Sul, tem crescido, especialmente na última década. O objetivo deste trabalho foi comparar a dinâmica, a produção de matéria seca, a qualidade e a composição botânica de pastagens de Coastcross-1 (Cynodon dactylon $x$ C. nlemfluensis) e milheto (Pennisetum americanum) $\mathrm{cv}$. Comum, sob sistema de pastejo rotacionado, com vacas em lactação da raça Holandês. Avaliaram-se a massa de forragem no pré-pastejo (MFPP), a taxa de acúmulo diário de matéria seca (TAD), a produção total de forragem (PTF) e a composição botânica das pastagens. Para o milheto e a Coastcross-1, foram avaliados os componentes estruturais: lâmina foliar (LF), colmo + bainha (CB), outras espécies $(O E)$ e material morto (MM). Na entrada e saída dos animais da pastagem, foram colhidas amostras por simulação de pastejo para determinação dos teores de proteína bruta $(P B)$ e fibra em detergente neutro (FDN). Não houve diferença significativa $(P>0,05)$ para MFPP, TAD, PTF e PB. O milheto apresentou maior disponibilidade de lâminas foliares $(P<0,05)$, menor teor de FDN $(P<0,05)$ na entrada e saída dos animais da pastagem e maior participação de $\mathrm{OE}(\mathrm{P}<0,05)$. O período total de pastejo foi maior na pastagem de Coastcross-1.

Palavras-chave: composição botânica, pastagens tropicais, pastejo rotacionado.

\section{ABSTRACT}

The use of pastures of the genus Cynodon has increased, for the last decade especially in dairy properties of Rio Grande do Sul. This research aims to compare the dynamic, dry matter production, quality and botanical composition of Coastcross-1 (Cynodon dactylon x C. nlemfluensis) and pearl millet (Pennisetum americanum) cv. Comum pastures. The pastures were utilized by lactating Holstein dairy cows under rotational stocking system. Pregraze dry matter availability
(DMA), daily dry matter accumulation rate (DMR), total dry matter production (TDM) were evaluated. For the botanical composition, the structural components: leaf blade (LB), stem + sheat (SS), dead material (DMT) of pastures and other species (OS) were evaluated. Before and after grazing, samples were collected by hand-plucking in order to determine the crude protein concentration (CP) and neutral detergent fiber (NDF). No significant difference $(P>.05)$ was observed to DMA, DMR, TDM and CP. Pearl millet presented greater availability of $L B$ $(P<.05)$, smaller NDF $(P<.05)$ in pregraze and postgraze herbage mass and greater contribution of OS $(P<.05)$. The total grazing period was greater in Coastcross-1 pasture.

Key words: botanical composition, tropical pastures, rotational grazing.

\section{INTRODUÇÃO}

Na bovinocultura de leite, a alimentação é o componente de maior participação no custo da produção. Durante o período estival, em diferentes regiões do Rio Grande do Sul, as forrageiras das propriedades leiteiras são constituídas, especialmente, por pastagens naturais e cultivadas. Dentre essas, destaca-se o milheto, que se caracteriza por apresentar elevada produção e qualidade de forragem e adaptação a diversos tipos de solo (SANTOS et al., 2002). Seu estabelecimento normalmente é feito em áreas utilizadas com espécies anuais de inverno, implicando custos elevados em insumos e maquinário agrícola, além de perdas de solo, especialmente se o preparo da área for convencional, em comparação à utilização de pastagens perenes.

\footnotetext{
ICurso de Zootecnia, Universidade Federal de Santa Maria (UFSM), Santa Maria, RS, Brasil.

IIDepartamento de Zootecnia, UFSM, Santa Maria, RS, Brasil. Endereço para correspondência: Condomínio Vila Verde, 13, Faixa Velha, Camobi, 97110-620, Santa Maria, RS, Brasil. E-mail: clairo@ccr.ufsm.br
} 
Na Meso-região Noroeste, responsável por cerca de 70 \% da produção de leite do Estado do RS e em outras regiões, tem-se intensificado o uso de pastagens perenes do gênero Cynodon spp. (especialmente Tifton e Coastcross). Sistemas forrageiros constituídos por estas pastagens caracterizam-se por apresentar elevado potencial de produção de forragem, alta lotação animal e longo período de utilização, além de permitirem a associação com espécies de ciclo hibernal (BORTOLO et al., 2001; ALVIM\& BOTREL, 2001).

Embora se saiba do potencial dessas pastagens, pesquisas e informações científicas sobre sistemas de produção de leite constituídos por estas espécies são escassas. O objetivo deste trabalho foi comparar a dinâmica, a produção e a qualidade de pastagens de Coastcross-1 e milheto, quando utilizadas com vacas em lactação.

\section{MATERIAL E MÉTODOS}

O trabalho foi realizado no período de dezembro de 2004 a abril de 2005, em área localizada na região fisiográfica da Depressão Central do Rio Grande do Sul, com altitude de $95 \mathrm{~m}$, latitude de $29^{\circ} 43^{\prime}$ Sul e longitude de $53^{\circ} 42^{\prime}$ Oeste. Conforme dados da Estação Meteorológica da UFSM, situada a 500 metros do local da experimentação, as médias mensais de temperatura e precipitação dos últimos 30 anos, correspondentes ao período experimental, são de $22^{\circ} \mathrm{C}$ e $139 \mathrm{~mm}$, respectivamente. No período de realização da pesquisa, nos meses de dezembro de 2004, janeiro, fevereiro, março e abril de 2005, as temperaturas médias mensais foram de 23,$8 ; 25,9 ; 24,3 ; 23,7$ e $19,1^{\circ} \mathrm{C}$ e as precipitações foram de 62,$2 ; 49,8 ; 59,4 ; 55,4$ e 276,1mm, respectivamente.

O solo da área experimental é classificado como Argissolo Vermelho Distrófico Arênico (EMBRAPA, 1999). O clima da região é o Cfa (subtropical úmido), conforme classificação de Köppen. A análise de solo revelou os seguintes valores médios: $\mathrm{pH}-\mathrm{H}_{2} \mathrm{O}$ 5,2; Índice SMP 5,6; argila 22\%; $\mathrm{P}$ 15,4mg L ${ }^{-1}$; K 43mg L ${ }^{-1}$; MO 3,3\%; Al 1,0 cmolc L-1; Ca 3,6cmolc $\mathrm{L}^{-1}$; Mg 1,6cmolc $\mathrm{L}^{-1}$; saturação de bases $50 \%$ e saturação por alumínio 16\%. A área experimental, de 1,2ha, foi subdividida em cinco piquetes, de aproximadamente 0,25 ha cada, sendo um piquete utilizado para adaptação dos animais.

Foram avaliadas duas pastagens de estação quente (tratamentos), sendo a Coastcross-1 (Cynodon dactylon x C.nlemfluensis) e o milheto (Pennisetum americanum) cv. "Comum", em um delineamento experimental completamente casualizado com duas repetições de área e em parcelas subdivididas no tempo (períodos de avaliação/pastejos).

A pastagem de Coastcross-1 já havia sido implantada em março de 2003, manualmente, por meio de mudas. No período hibernal, parte da área (três piquetes) foi utilizada com pastagens anuais (aveia e azevém). Na área de Coastcross-1, fez-se, em outros dois piquetes, a sobre-semeadura com estas espécies. No período estival, fez-se o estabelecimento de milheto nos piquetes onde havia aveia e azevém. Para o preparo do solo, foram realizadas duas gradagens. As sementes foram distribuídas a lanço $\left(50 \mathrm{~kg} \mathrm{ha}^{-1}\right)$, considerandose $100 \%$ de germinação. Para incorporação, foi utilizado rolo compactador. Na área de Coastcross-1, fez-se uma roçada para uniformizar a pastagem no dia 10 de novembro de 2004. A adubação utilizada foi de acordo com a análise de solo para as respectivas culturas. Como adubação de cobertura, utilizou-se $80 \mathrm{~kg} \mathrm{ha}^{-1}$ de nitrogênio, na forma de uréia, divididos em quatro aplicações na pastagem de Coastcross-1 e três aplicações na pastagem de milheto.

A massa de forragem (MFPP) foi avaliada antes de cada pastejo, através da técnica de dupla amostragem (WILM et al., 1944), com cinco cortes e 15 estimativas visuais por repetição. A forragem proveniente das amostras cortadas foi homogeneizada e, posteriormente, uma amostra foi retirada para estimativa dos componentes estruturais (lâmina foliar, colmo + bainha, material senescente) de cada espécie forrageira, determinando-se ainda a presença de outras espécies (OE); e outra para determinar o teor de matéria seca (MS). As amostras foram secadas em estufa de ar forçado a $65^{\circ}$ para estimativa do percentual de cada componente com base na MS. A MFPP foi utilizada também para cálculo da carga animal, usando-se uma oferta de forragem de $8 \mathrm{~kg}$ de MS por $100 \mathrm{~kg}$ de peso vivo, aproximadamente.

O período de avaliação foi diferenciado de acordo com a espécie, sendo de 19/01 a 04/04 para a Coastcross-1 e 26/01 a 20/03 para o milheto. O período de utilização da pastagem de milheto foi de 53 dias e 75 dias para a Coastcross-1. Os pastejos foram realizados nos dias 22/01, 07/02, 04/03, 01/04 na pastagem de Coastcross-1 e nos dias 29/01, 11/02, 18/03 no milheto. O tempo de ocupação em cada ciclo de pastejo foi, em média, de três dias. O método de pastejo foi rotacionado, utilizando-se vacas em lactação da raça Holandês, com cerca de $500 \mathrm{~kg}$ de peso vivo e produção diária de leite de 14,32 l. Cada animal recebeu diariamente, como complementação alimentar, $3 \mathrm{~kg}$ de concentrado.

A estimativa da taxa de acumulação diária de MS (TAD, em kg ha ${ }^{-1} \mathrm{dia}^{-1}$ ) foi feita a cada 28 dias, utilizando-se duas gaiolas de exclusão ao pastejo por 
unidade experimental. Cada amostra era proveniente de uma área de $0,25 \mathrm{~m}^{2}$. A TAD do período foi estimada por intermédio da equação descrita por CAMPBELL (1966). A produção total de MS (PTF) foi calculada pelo somatório das produções dos períodos (taxa de acúmulo diário $\mathrm{x}$ número de dias do período) mais a massa de forragem inicial. A estimativa do percentual de produção de MS dos componentes estruturais das espécies da pastagem foi obtida dividindo a produção destes, em cada período, pela produção total de MS do mesmo, multiplicado por 100.

Na entrada e saída dos animais da pastagem, foram colhidas amostras por meio de simulação de pastejo (EUCLIDES et al., 1992), realizada por dois observadores treinados, para determinação do teor de proteína bruta (PB) e fibra em detergente neutro (FDN) da forragem aparentemente consumida pelos animais. As amostras colhidas foram pesadas, secadas em estufa de ar forçado a $65^{\circ}$ e moídas em moinho tipo Willey.

Os resultados foram submetidos à análise de variância. Quando detectadas diferenças, as médias foram comparadas considerando-se o nível de 5\% de significância. As variáveis que apresentaram interação entre tratamento e período de avaliação foram submetidas ao teste de regressão polinomial ao nível de 5\%. Para variáveis que não apresentaram interação significativa entre tratamento e período de avaliação $(\mathrm{P}>0,05)$, foi feita a análise de regressão considerandose a totalidade das informações, ao nível de 5\%. Foi feita análise de correlação (PROC CORR) para verificar possíveis associações entre os parâmetros avaliados. Todas as análises foram realizadas utilizando-se o pacote estatístico SAS versão 6.12 (1997). O modelo estatístico geral referente à análise das variáveis estudadas foi representado por: $\mathrm{Y}_{\mathrm{ij}}=\mu+\mathrm{T}_{\mathrm{i}}+\mathrm{P}_{\mathrm{j}}+\mathrm{T}_{\mathrm{i}} \mathrm{P}_{\mathrm{j}}+$ $\varepsilon_{i j}$, no qual Yij representa as variáveis dependentes; $\mu$ é a média de todas as observações; Ti corresponde ao i-ésimo tratamento; Pj corresponde ao j-ésimo período de avaliação (pastejos); TiPj é a interação entre o iésimo tratamento e o j-ésimo período; e $\varepsilon_{\mathrm{ij}}$ corresponde ao erro experimental residual.

\section{RESULTADOS E DISCUSSÃO}

Na tabela 1, estão apresentados os valores de MFPP, teor de MS, carga animal, TAD e os teores de $\mathrm{PB}$ e FDN da pastagem. Houve interação $(\mathrm{P}<0,05)$ entre tratamentos e período de avaliação para o teor de MS das pastagens. Observa-se que os teores de MS da Coastcross-1 mantiveram-se elevados, acima de 30\%, em todas as avaliações. Já os valores do milheto apresentaram comportamento ascendente com o decorrer dos pastejos, condição normalmente esperada para a espécie (HERINGER \& MOOJEN, 2002).

Para os parâmetros MFPP, TAD, PB e FDN, não houve interação $(\mathrm{P}>0,05)$ entre espécies forrageiras e períodos de avaliação. Não houve diferença significativa $(\mathrm{P}>0,05)$ entre os valores médios de massa de forragem pré-pastejo. A média observada no milheto

Tabela 1 - Massa de forragem de pré-pastejo (MFPP), teor de matéria seca (MS), carga animal (CA), taxa de acúmulo diária de MS (TAD) e teores de proteína bruta (PB) e fibra em detergente neutro (FDN) de pastagens de Coastcross-1 e milheto, utilizadas no período estival. Santa Maria, 2005.

\begin{tabular}{|c|c|c|c|c|c|c|c|c|}
\hline \multicolumn{9}{|c|}{ Parâmetros } \\
\hline \multirow{2}{*}{$\begin{array}{l}\text { Datas de } \\
\text { avaliação }\end{array}$} & \multirow{2}{*}{$\begin{array}{c}\text { MFPP } \\
\text { (t de MS.ha }^{-1} \text { ) }\end{array}$} & \multirow{2}{*}{$\begin{array}{l}\text { MS } \\
(\%)\end{array}$} & \multirow{2}{*}{ CA Kg PV.ha ${ }^{-1}$} & \multirow{2}{*}{$\begin{array}{c}\text { TAD } \\
\text { kg MS.ha.dia } \\
\text { (1) }\end{array}$} & \multicolumn{2}{|c|}{ PB (\%) } & \multicolumn{2}{|c|}{ FDN (\%) } \\
\hline & & & & & Pré-pastejo $^{1}$ & Pós-pastejo ${ }^{2}$ & Pré-pastejo & Pós-pastejo \\
\hline \multicolumn{9}{|c|}{ Coastcross-1 } \\
\hline $22 / 01$ & 3,75 & 33,17 & 6,50 & 41,90 & 16,97 & 18,61 & 64,58 & 71,95 \\
\hline 07/02 & 3,30 & 33,68 & 5,70 & 176,20 & 15,64 & 15,40 & 59,07 & 71,02 \\
\hline 04/03 & 3,86 & 37,88 & 4,30 & 33,05 & 14,38 & 8,44 & 68,27 & 76,99 \\
\hline $01 / 04$ & 3,70 & 33,93 & 3,70 & 85,36 & 11,76 & 14,75 & 67,98 & 71,93 \\
\hline Médias & $3,65^{\mathrm{A}}$ & $34,66^{\mathrm{A}}$ & $5,05^{\mathrm{A}}$ & $84,10^{\mathrm{A}}$ & $14,68^{\mathrm{A}}$ & $14,30^{\mathrm{A}}$ & $64,97^{\mathrm{A}}$ & $72,97^{\mathrm{A}}$ \\
\hline CV(\%) & 14,70 & 0,98 & 13,12 & 36,14 & 11,01 & 14,32 & 2,20 & 2,20 \\
\hline \multicolumn{9}{|c|}{ Milheto } \\
\hline 29/01 & 4,00 & 16,03 & 8,60 & 88,00 & 22,93 & 22,45 & 58,97 & 65,38 \\
\hline $11 / 02$ & 3,57 & 18,32 & 7,60 & 225,20 & 16,22 & 16,04 & 57,91 & 65,38 \\
\hline $18 / 03$ & 5,14 & 25,11 & 4,10 & 100,75 & 15,88 & 11,80 & 55,29 & 61,21 \\
\hline Médias & $4,24^{\mathrm{A}}$ & $19,82^{\mathrm{B}}$ & $6,75^{\mathrm{B}}$ & $129,50^{\mathrm{A}}$ & $18,34^{\mathrm{A}}$ & $16,77^{\mathrm{A}}$ & $57,39^{\mathrm{B}}$ & $62,82^{\mathrm{B}}$ \\
\hline CV(\%) & 15,63 & 0,14 & 16,70 & 48,50 & 5,90 & 6,14 & 4,06 & 6,90 \\
\hline
\end{tabular}

${ }^{\text {A B }}$ Médias com letras diferentes na linha diferem entre si $(\mathrm{P}<0,05)$. 1Proteína bruta: $\mathrm{Y}=18,998-0,10 ; \mathrm{P}=0,003 ; \mathrm{R}^{2}=0,53$.

2Proteína bruta: $\mathrm{Y}=21,42-0,52 \mathrm{X}+0,006 \mathrm{X}^{2} ; \mathrm{P}=0,0006 ; \mathrm{R}^{2}=0,82$. 
é superior à preconizada por RESTLE et al. (2002) e SANTOS et al. (2005), que trabalharam com valores entre 2.000 e $2.500 \mathrm{~kg}$ de MS ha-1. Os reflexos da manutenção da disponibilidade de forragem acima destes valores estão associados à menor proporção de lâminas, resultante da menor taxa de aparecimento das folhas novas (MARTINS et al., 2005) e maiores perdas pelos processos de senescência e morte (CARNEVALLI et al., 2001). O valor médio de massa de forragem no pré-pastejo da Coastcross-1, obtido neste experimento, é semelhante ao utilizado por ALVIM et al. (2003). BORTOLO et al. (2001), entretanto, verificaram que melhores parâmetros produtivos da pastagem de Coastcross-1 são obtidos quando mantidas disponibilidades de $2.100 \mathrm{~kg}$ de MS ha-1, aproximadamente.

ATAD não diferiu $(\mathrm{P}>0,05)$ entre as espécies avaliadas. A TAD média verificada para a Coastcross1 está entre os valores observados por CARNEVALLI et al. (2001), de 85 a $100 \mathrm{~kg}$ de MS ha-1 $\mathrm{dia}^{-1}$, e inferior aos valores médios descritos por PINTO et al. (2001), de $142 \mathrm{~kg}$ de $\mathrm{MS} \mathrm{ha}^{-1} \mathrm{dia}^{-1}$, sob condições de clima tropical. FAGUNDES et al. (1999) descrevem um comportamento uniforme da TAD da Coastcross- 1 no decorrer da estação de crescimento. Esse comportamento, entretanto, está associado à disponibilidade de nutrientes e de umidade no solo. Possivelmente as oscilações verificadas na TAD da Coastcross-1 devem-se, especialmente, às baixas precipitações ocorridas entre dezembro e março, que ficaram abaixo de $50 \%$ da média climática. Segundo MELO et al. (2001), a oscilação que ocorre na taxa de acumulação de MS das pastagens, devido às variações climáticas e à estacionalidade de produção das espécies utilizadas, é a maior dificuldade enfrentada no manejo de pastagens, principalmente para aqueles baseados em sistema de pastejo contínuo. A TAD média do milheto foi $85,33 \mathrm{~kg} \mathrm{MS} \mathrm{ha-1} \mathrm{dia}^{-1}$, sendo similar aos valores descritos por LUPATINI et al. (1996). A produção total de forragem foi de 11,1 t de $\mathrm{MS} \mathrm{ha}^{-1}$ para a Coastcross-1 e 10,7t de MS ha-1 para o milheto. Segundo CARNEVALLI et al. (2001), a produção de MS anual média da Coastcross-1 pode chegar a 23t ha $^{-1} \mathrm{ano}^{-1}$. O milheto pode superar uma produção de MS de $15 \mathrm{tha}^{-1}$, quando submetido a altos níveis de adubação nitrogenada (LUPATINI et al., 1996).

A similaridade observada entre as pastagens para os parâmetros de produção de forragem demonstra que cada espécie pode ser usada em distintas estratégias de produção, de acordo com suas características fenológicas, esperando-se resultados semelhantes. Desta forma, a Coastcross-1, como espécie perene, apresenta maior período de utilização, além de permitir a sobre-semeadura com forrageiras de ciclo hibernal (CARNEVALLI et al., 2001; ALVIM et al, 2003). O milheto, por ser anual, pode ser utilizado estrategicamente, no verão e outono, para a Depressão Central do RS, para se produzir grande quantidade de matéria seca em curto período de tempo. Além disso o milheto permite a sua associação com outras forrageiras, podendo ser usado em sistemas com rotação de culturas (SANTOS et al., 2002).

Houve interação $(\mathrm{P}<0,05)$ entre tratamentos e período de avaliação para a carga animal. A carga animal média observada foi de 5,0UA ha-1 na pastagem de Coastcross-1, sendo superior à verificada por ALVIM \& BOTREL (2001), e 6,7UA ha ${ }^{-1}$ em pastagem de milheto. PRADO et al. (2003), avaliando esta pastagem, obtiveram carga de 2,77UA ha ${ }^{-1}$ utilizando novilhos mestiços Nelore x Girolando.

Com relação a qualidade da pastagem, avaliada a partir de amostras de pastejo simulado, não houve diferença significativa $(\mathrm{P}>0,05)$ para os teores de $\mathrm{PB}$. Os teores de PB decresceram com o avanço do período de utilização das pastagens (Tabela 1). Tendo em vista as diferenças na composição química de folhas e colmos, esse comportamento é esperado, em função da variação nas proporções desses componentes, na medida em que avança o ciclo das forrageiras. Os valores de PB verificados no milheto foram superiores aos encontrados por RESTLE et al. (2002) de 10,58\%. Segundo SANTOS et al. (2002) o teor de PB do milheto pode variar de 7 a $20 \%$, dependendo do manejo e da fertilização. Os valores de PB verificados na Coastcross1 são superiores aos relatados por BORTOLO et al. (2001), de 9,16 a 10,04\%.

Para os valores médios de FDN, foram encontradas diferenças significativas $(\mathrm{P}<0,05)$ entre as espécies forrageiras. Os maiores teores foram detectados na Coastcross-1, tanto no pré, quanto no pós-pastejo. PRADO et al. (2003) encontraram valores de FDN das lâminas foliares em pastagem de milheto semelhantes aos obtidos neste experimento. Os valores médios de FDN da Coastcross-1 estão de acordo com os descritos por CARNEVALLI et al. (2001), entre 63 e $74 \%$.

Correlações normalmente esperadas entre FDN e PB foram encontradas em amostras de póspastejo, sendo de $-0,80(\mathrm{P}<0,01)$ para ambas as forrageiras. Detectou-se associação da PB de prépastejo com massa de lâminas foliares $(0,95 ; \mathrm{P}<0,01)$ com a carga animal $(0,96 ; \mathrm{P}<0,001)$. A PB do pós-pastejo apresentou associação com a massa de lâminas foliares $(0,95 ; \mathrm{P}<0,01)$, carga animal $(0,84 ; \mathrm{P}<0,05)$ e TAD $(0,77$; $\mathrm{P}<0,05)$. Comparativamente, com relação a estes parâmetros, apenas a TAD apresentou correlação com 
a $\mathrm{PB}$ ao pós-pastejo $(0,77 ; \mathrm{P}<0,05)$. Houve associação entre os teores de FDN do milheto e da Coastcross-1 com a massa de colmos (0,75; $\mathrm{P}<0,05$ e 0,75 ; $\mathrm{P}<0,05)$.

Estruturalmente, foram observados comportamentos diferenciados entre as pastagens (Figura 1). Dentre as variáveis, o componente lâmina foliar (LF) apresentou interação entre tratamento e período de avaliação $(\mathrm{P}<0,05)$. Na pastagem de milheto, a participação de LF apresentou comportamento quadrático ( $\mathrm{Y}=2499,93$ - 99,81X + 1,4X²; $\left.\mathrm{R}^{2}=0,95\right)$. Resultado similar também foi evidenciado no trabalho de LUPATINI et al. (1996). Não houve ajuste de equação para LF da Coastcross-1. As disponibilidades médias de LF foram de $1,58 \mathrm{t}$ de $\mathrm{MS} \mathrm{ha}^{-1}$ em pastagem de milheto e 1,12t de MS ha-1 na Coastcross-1.

Não houve diferença $(\mathrm{P}>0,05)$ entre espécies avaliadas para o componente colmo + bainha (CB). Houve acréscimo linear na participação de CB, ao longo do período de utilização ( $Y=1468,37+9,48 X$; $\left.\mathrm{R}^{2}=0,39\right)$. A participação de material morto (MM) não diferiu $(\mathrm{P}>0,05)$ entre a Coastcross-1 e o milheto. OLIVEIRA et al. (2000) descrevem a senescência foliar como um processo natural que caracteriza a última fase de desenvolvimento de uma folha. Este processo pode ser acelerado pela ação de fatores de meio como competição por luz, água e nutrientes. LUPATINI et al. (1996) também verificaram baixa contribuição de MM no início do período de utilização de pastagens de milheto, aumentando com o decorrer do tempo.

Com relação à participação de $\mathrm{OE}$, verificouse diferença significativa $(\mathrm{P}<0,05)$ entre as pastagens. Na pastagem de milheto, a presença de OE aumentou gradativamente, chegando a 32\% no final do período de utilização. LUPATINI et al. (1996) verificaram a contribuição expressiva de OE em pastagem de milheto durante todo o período de utilização. Na pastagem de Coastcross-1, a participação média de OE não superou $10 \%$ da composição vegetal. A disponibilidade média de OE foi de 0,132 t de MS ha-1 em pastagem de Coastcross-1 e 0,753t de MS ha ${ }^{-1}$ na pastagem de milheto. A vantagem na competição com outras espécies, demonstrada pela Coastcross-1, está ligada a sua característica de espécie perene e, principalmente, ao seu hábito de crescimento estolonífero, comparada ao milheto, que é uma espécie anual possuindo hábito de crescimento cespitoso.

\section{CONCLUSÕES}

Pastagens de Coastcross- 1 e milheto apresentam produção de forragem, teores de proteína bruta e carga animal semelhantes.

O milheto apresenta menor teor de fibra em detergente neutro, em decorrência de uma maior disponibilidade de lâminas foliares, comparado à Coastcross-1.

A Coastcross-1 apresenta participação mais estável de lâminas foliares, no decorrer dos pastejos, e menor participação de outras espécies na forragem disponível.

\section{REFERÊNCIAS}

ALVIM, M.J.; BOTREL, M.A. Efeitos de doses de nitrogênio na produção de leite de vacas em pastagem de coast-cross. Pesquisa Agropecuária Brasileira, Brasília, v.36, n.3, p.577-583, 2001.

ALVIM, M.J. et al. Avaliação sob pastejo do potencial forrageiro de gramíneas do gênero Cynodon, sob dois níveis de nitrogênio e potássio. Revista Brasileira de Zootecnia, Viçosa, v.32, n.1, p.47-54, 2003.

BORTOLO, M. et al. Desempenho de ovelhas, composição química e digestibilidade in vitro em uma pastagem de coastcross-1 (Cynodon dactylon (L.) Pers) sob diferentes níveis de matéria seca residual. Revista Brasileira de Zootecnia, Viçosa, v.30, n.3, p.636-643, 2001

CAMPBELL, A.G. Grazed pastures parameters. I. Pasture dry matter production and availability in a stocking rate and grazing management experiment with dairy cows. Journal of Agriculture Science, Cambridge, v.67, p.211-216, 1966. 
CARNEVALLI, R. A. et al. Desempenho de ovinos e respostas de pastagens de coastcross submetidas a regimes de desfolha sob lotação contínua. Pesquisa Agropecuária Brasileira, Brasília, v.36, n.6, p.919-927, 2001.

EMBRAPA. Centro Nacional de Pesquisa Agropecuária. Sistema brasileiro de classificação de solos. Rio de Janeiro: EMBRAPA, 1999. 412p.

EUCLIDES, V.P.B. et al. Avaliação de diferentes métodos para se estimar o valor nutritivo de forragens sob pastejo. Revista Brasileira de Zootecnia, Viçosa, v.21, n.4, p.691-702, 1992.

FAGUNDES, J.L. et al. Índice de área foliar, interceptação luminosa e acúmulo de forragem em pastagens de Cynodon spp. sob diferentes intensidades de pastejo. Scientia Agricola, Piracicaba, v.56, n.4, p.1141-1150, 1999.

HERINGER, I.; MOOJEN, E.L. Potencial produtivo, alterações da estrutura e qualidade da pastagem de milheto submetida a diferentes níveis de nitrogênio. Revista Brasileira de Zootecnia, Viçosa, v.31, n.2, p.875-882, 2002.

LUPATINI, G.C. et al. Resposta do milheto (Pennisetum americanum (L.) Leeke) sob pastejo à adubação nitrogenada. Pesquisa Agropecuária Brasileira, Brasília, v.31, n.10, p.715-720, 1996.

MARTINS, C.E.N. et al. Variáveis morfogênicas de milheto (Pennisetum americanum) mantido em duas alturas de pastejo. Ciência Rural, Santa Maria, v.35, n.1, p.174-180, 2005.

MELO, E.P. et al. Disponibilidade e composição química de forrageiras com diferentes hábitos de crescimento, pastejadas por ovinos. Acta Scientiarum, Maringá, v.23, n.4, p.973-980, 2001.
OLIVEIRA, M.A. et al. Características morfogênicas e estruturais do capim-bermuda “Tifton 85” (Cynodon spp.) em diferentes idades de rebrota. Revista Brasileira de Zootecnia, Viçosa, v.29, n.6, p.1939-1948, 2000.

PINTO, L.F.M. et al. Dinâmica do acúmulo de matéria seca em pastagens de tifton 85 sob pastejo. Scientia Agricola, Piracicaba, v.58, n.3, p.439-447, 2001.

PRADO, I.N. et al. Sistemas para crescimento e terminação de bovinos de corte a pasto: avaliação do desempenho animal e características da forragem. Revista Brasileira de Zootecnia, Viçosa, v.32, n.4, p.955-965, 2003.

RESTLE, J. et al. Produção animal em pastagem com gramíneas de estação quente. Revista Brasileira de Zootecnia, Viçosa, v.31, n.3, p.1491-1500, 2002.

SANTOS, D.T. et al. Suplementos energéticos para recria de novilhas de corte em pastagens anuais. Desempenho animal. Revista Brasileira de Zootecnia, Viçosa, v.34, n.1, p.209219, 2005.

SANTOS, H.P. et al. Principais forrageiras para integração lavoura-pecuária, sob plantio direto, nas Regiões Planalto e Missões do Rio Grande do Sul. Passo Fundo: Embrapa Trigo, 2002. 142p.

SAS INSTITUTE. SAS/STAT software: changes and enhancements through release 6.12. Cary, 1997. 1167p.

WILM, H.G. et al. Estimating forage yield by the double sampling method. Journal of the American Society for Agriculture, v.36, n.1, p.194-203, 1944. 